\title{
A EDUCAÇÃO PROFISSIONAL NA MODALIDADE DE EDUCAÇÃO DE JOVENS E ADULTOS: A EXPERIÊNCIA DO PROEJA NO IFBA CÂMPUS DE BARREIRAS, NO PERÍODO DE 2006 - 2014
}

\author{
C. F. REIS ${ }^{1^{*}}$, P. VIELMO ${ }^{1}$ e J. M. CARDOSO ${ }^{2}$ \\ ${ }^{1}$ Instituto Federal de Educação, Ciência e Tecnologia da Bahia - Campus de Barreiras \\ ${ }^{2}$ Universidade Federal do Oeste da Bahia - UFOB \\ cacilda.freis@hotmail.com*
}

Artigo submetido em outubro/2014 e aceito em dezembro/2014

DOI: $10.15628 /$ rbept.2014.3492

\section{RESUMO}

Este artigo é resultado parcial de um estudo em desenvolvimento, que objetiva refletir sobre o Programa Nacional de Integração da Educação Profissional com a Educação Básica na Modalidade de EJA, no âmbito da Rede Federal de Educação Profissional, Científica e Tecnológica, analisando a experiência do PROEJA no IFBA Campus de Barreiras, identificando os impasses e avanços que emergiram na implantação do Programa. Neste artigo analisamos a documentação existente e trajetória dos (as) estudantes. A pesquisa, de caráter qualitativo, constituiu-se em um estudo de caso, que compreendeu o levantamento bibliográfico e a análise documental. A pesquisa empírica envolveu a análise da trajetória dos (as) estudantes do curso de Eletromecânica, de 2006 a 2014. Os dados preliminares indicam, como verificando no cenário nacional, a dificuldade da consolidação do Programa no Campus de Barreiras. Contatou-se ainda um quadro de elevado índice de reprovação/retenção, abandono/evasão e um reduzido nível de atração entre o público em geral e público alvo, em particular e uma baixa presença de mulheres ingressas e concluintes.

PALAVRAS-CHAVE: Educação Profissional, trabalho, PROEJA, gênero.

\section{PROFESSIONAL EDUCATION IN THE YOUTH AND ADULT EDUCATION: THE PROEJA EXPERIENCE IN IFBA CAMPUS BARREIRAS IN THE PERIOD 2006 - 2014}

\begin{abstract}
This article is the partial result of a study in development, which aims to reflect on the National Programme for professional Education Integration with Basic Education, EJA mode within the Federal Network of Professional Education, Science and technology, analyzing the experience of PROEJA on IFBA Campus Barreiras, identifying the impasses and advances that have emerged in the implementation of the Program. In this article we analyze existing data and the trajectory the students the students. The qualitative research, consisted in a case study, which included the literature
\end{abstract}

and document analysis. The empirical research involved the analysis of the trajectory the students of Electromechanical course from 2006 to 2014. Preliminary data indicate, as checking on the national scene, the difficulty of the consolidation of the program in the Campus Barreiras. It also contacted a high frame rate of failure / retention, dropout / evasion and a low level of attraction between the general public and target audience in particular and a low presence of newcomer and graduating women.

KEYWORDS: Professional education, work, PROEJA, genre. 


\section{INTRODUÇÃO}

No Brasil, a Educação Profissional, nas últimas décadas, passou por inúmeras reformas, em virtude dos modelos políticos e de desenvolvimento econômicos adotados pelos governos. Situamos, no contexto dessas mudanças, a adoção de uma proposta inédita de integrar a Educação Profissional com a EJA com a criação do Programa Nacional de Integração da Educação Profissional com a Educação Básica na Modalidade de Educação de Jovens e Adultos/PROEJA, por meio do Decreto n.o 5.478/2005, substituído pelo Decreto n.o 5.840/2006, que introduz novas diretrizes ampliando a abrangência desse Programa.

Para o Ministério da Educação (BRASIL/MEC, 2007a, p. 5), a ampliação do PROEJA aponta novos desafios para a construção e a consolidação de uma "proposta educacional que se pretende parte de uma política de inclusão social". Ressalta a necessidade do reconhecimento, do respeito e do diálogo com o saber que porta o (a) aluno (a) trabalhador (a); pressupondo nessa direção o "acatamento de tempos e espaços diferenciados, bem como processos contínuos de construção coletiva de conhecimentos".

A Educação Profissional e Tecnológica relacionada à Educação de Jovens e Adultos é um campo teórico em consolidação e por atuarmos na Coordenação Técnico-Pedagógica, no âmbito do Serviço Social e da Pedagogia, acompanhando os cursos nas diversas modalidades, decidimos por realizar o presente estudo, que consiste na reflexão acerca do Programa Nacional de Integração da Educação Profissional com a Educação Básica na Modalidade de EJA, a partir da experiência do curso Técnico em Eletromecânica, na modalidade PROEJA.

O objetivo geral da pesquisa consiste em identificar quais foram os impasses e os avanços que emergiram na implantação do Programa Nacional de Integração da Educação Profissional com a Educação Básica na Modalidade de EJA, tendo como referência a experiência do curso Técnico em Eletromecânica, na modalidade PROEJA, desenvolvido entre os anos 2006 a 2014.

\section{REVISÃO BIBLIOGRÁFICA}

Historicamente, a Educação de Jovens e Adultos (EJA) no Brasil tem sido marcada por práticas assistencialistas, de grupos isolados ou até mesmo iniciativas individuais, sobretudo no âmbito da alfabetização. Como modalidade nos níveis fundamental e médio, caracteriza-se pela descontinuidade e por tênues políticas públicas, insuficientes para dar conta da demanda e do direito constitucional estabelecido na Constituição Federal de 1988 (BRASIL/MEC, 2007b, p.09).

São inúmeros os motivos que levam os (as) jovens e adultos (as) a abandonarem a escola, como por exemplo, questões socioeconômicas das famílias, que necessitam retirar os filhos e filhas da escola para trabalhar (sobretudo no ensino fundamental) e também o desinteresse causado pela própria escola (particularmente no ensino médio), desvinculada da realidade daqueles (as) jovens. No entanto, mais tarde essas pessoas retornam, via EJA, convictas da falta que faz a escolaridade em suas vidas, acreditando que a negativa em postos de trabalho e lugares de emprego se associa à baixa escolaridade.

Observamos assim que a EJA, em síntese, trabalha com sujeitos marginais ao sistema, o que torna fundamental uma política pública estável que contemple a elevação da escolaridade com profissionalização, no sentido de contribuir para a integração sociolaboral desse grande 
contingente de cidadãos cerceados do direito de concluir a educação básica e de ter acesso a uma formação profissional de qualidade (BRASIL/MEC, 2007b, p.11).

No entanto, antes do Decreto de criação do PROEJA, temos a Resolução CNE/CEB № 1, de 15 de julho de 2000, que "estabelece Diretrizes Curriculares Nacionais para a Educação de Jovens e Adultos", citando timidamente em seu Art. 2o Educação Básica e Educação Profissional, possibilitando relacionar ambas: "a presente Resolução abrange os processos formativos da Educação de Jovens e Adultos como modalidade da Educação Básica nas etapas dos ensinos fundamental e médio, nos termos da Lei de Diretrizes e Bases da Educação Nacional, em especial dos seus artigos 4오 5ㅇ, 37, 38, e 87 e, no que couber, da Educação Profissional".

Diante disso, emerge a necessidade de pressionar os governos por políticas públicas duradouras nessa esfera, que desenvolva ações baseadas em princípios epistemológicos que resultem em um corpo teórico bem estabelecido e que respeite as dimensões sociais, econômicas, culturais, cognitivas e afetivas do jovem e do adulto em situação de aprendizagem escolar. É nesse contexto que surge o PROEJA.

Assim, buscou-se integrar três modalidades: Educação Básica, EJA e Educação Profissional, tomando-se a Rede Federal de Educação Profissional e Tecnológica como lócus inicial privilegiado para execução do Programa. O Decreto no. 5.478, de 24/06/2005 introduziu a Integração da Educação Profissional ao Ensino Médio na Modalidade Educação de Jovens e Adultos, para atender a demanda deste público pela oferta de educação profissional técnica de nível médio.

Anteriormente ao Decreto, algumas instituições da Rede Federal já desenvolviam experiências de Educação Profissional com Jovens e Adultos, mas nenhuma na modalidade integrada. Nesses termos, a revogação do Decreto no 5.478/2005, pela promulgação do Decreto no 5.840/2006, trouxe diversas mudanças para o Programa, entre elas a ampliação da abrangência, incluindo o ensino fundamental e abrindo para que instituições dos sistemas de ensino estaduais e municipais e entidades privadas nacionais de serviço social, aprendizagem e formação profissional fossem habilitadas para ofertar o PROEJA.

A partir de então, passou a ser denominado como Programa Nacional de Integração da Educação Profissional com a Educação Básica na Modalidade de Educação de Jovens e Adultos. O Programa pauta-se em seis princípios, a saber: 1) Inclusão da população em suas ofertas educacionais; 2) Inserção orgânica da modalidade EJA integrada à educação profissional nos sistemas educacionais públicos; 3) Ampliação do direito à educação básica, pela universalização do ensino médio; 4) Trabalho como princípio educativo; 5) Pesquisa como fundamento da formação; e 6) Condições geracionais, de gênero, de relações étnico-raciais como fundantes da formação humana e dos modos como se produzem as identidades sociais.

Entre os princípios para o PROEJA, destacamos acima, será abordado neste artigo o trabalho como princípio educativo e as condições de gênero. Por essa vertente, escola e trabalho vinculam-se não pela relação com a ocupação profissional diretamente, mas pelo entendimento de que homens e mulheres produzem sua condição humana pelo trabalho - ação transformadora no mundo, de si, para si e para outrem. (BRASIL, 2007b, p. 40).

Verificamos que a histórica dicotomia entre trabalho intelectual e trabalho manual, antes explícita na concepção de educação profissional começa a se modificar. É, portanto, "um desafio para a política de Educação de Jovens e Adultos reconhecer o trabalho como princípio educativo, 
primeiro por sua característica ontológica e, a partir disto, na sua especificidade histórica, o que inclui o enfrentamento das instabilidades do mundo contemporâneo" (FRIGOTTO et all, 2005, p. 12).

O quarto princípio implica colocar o trabalho como eixo central para democratizar o saber científico, tecnológico e histórico-crítico, a partir da compreensão de que o trabalho permeia todas as dimensões da vida humana. Por isso, o trabalho assumido como princípio educativo, deve integrar-se com a ciência, a tecnologia e a cultura como base da proposta político-pedagógica e do desenvolvimento curricular.

Esse princípio encontra respaldo, sobretudo, na produção de Gramsci, que desenvolveu uma proposta de "Escola Unitária ou Escola Humanista ou Escola de Cultura Geral”, em que critica fortemente a divisão entre "Escola para a cultura" e "Escola Técnica", ou seja, a divisão entre formações para o trabalho intelectual e para o trabalho manual, anunciados anteriormente. Gramsci defende uma "Escola Unitária", que significa "o início de novas relações entre trabalho intelectual e trabalho industrial não apenas na escola, mas em toda a vida social" (GRAMSCI, 1982, p. 125), refletindo em todos os organismos de cultura, transformando-os e emprestando-Ihes um novo conteúdo.

O sexto princípio indica atenção em relação à inclusão das questões de gênero no currículo, desnaturalizando a divisão sexual do trabalho, entendida como "a forma de divisão social do trabalho decorrente das relações sociais de sexo" (KERGOAT, 2009, p.67), destinando as mulheres historicamente aos espaços privados e reprodutivos e os homens aos espaços públicos e produtivos. Essa divisão sexual do trabalho separa os tipos de trabalhos: os de homens e os de mulheres e hierarquiza-os, sendo que o trabalho dos homens é considerado mais importante do que o das mulheres.

Acreditamos que o desafio consiste em perceber e considerar a divisão sexual do trabalho, resultando em desigualdades de gênero no mundo do trabalho, sobretudo no que trata da remuneração. Apesar das mulheres terem nível de escolaridade mais elevado que os homens, o rendimento desigual é elevado, mesmo se ocupando uma mesma função. Assim, "as questões de gênero devem ser ressaltadas uma vez que se enraíza em processos sociais, históricos, culturais e ideológicos em que a mulher ocupa lugar de inferioridade, rodeada de estereótipos e barreiras, que influenciam a caracterização da divisão sexual do trabalho, expressando relações de poder e hierarquização social dos gêneros" (RUAS e GARÍGLIO, [s/d], 2015). Não podemos deixar de pontuar o papel da educação e instituições escolares nesse contexto.

\section{METOdOLOGIA}

Adotamos na pesquisa a perspectiva qualitativa, visto que essa abordagem permite que 0 "mundo seja examinado com a ideia de que nada é trivial, que tudo tem potencial para constituir uma pista que nos permita estabelecer a compreensão mais esclarecedora do nosso objeto de estudo" (BOGDAN E BIKLEN, 1994, p. 49). Essa opção metodológica não significa o estabelecimento de uma oposição entre qualitativo/ quantitativo, na medida em que são modos diversos de resgatar a vida social e chegar a iluminar aspectos não aparentes e não conscientes para os (as) autores envolvidos (CARDOSO, 1986). Esses métodos devem ser tomados como complementares, pois apresentam modos diferentes de manifestação, funcionamento e dinâmica. 
O estudo de caso foi escolhido como técnica de coleta de dados, visto que permite retratar a realidade de forma completa e profunda, revelando a multiplicidade de dimensões presentes numa dada situação e focalizando-a como um todo, sem deixar de enfatizar os detalhes, as circunstâncias específicas que favorecem uma maior apreensão da totalidade (LAVILLE e DIONE 1999).

Os procedimentos e instrumentos envolveram na fase exploratória, que serviu de base para o presente artigo, o aprofundamento da bibliografia, visando assimilação das categorias teóricas que sustentarão a pesquisa; o contato inicial com a documentação existente, tais como decretos, pareceres, resoluções, projetos institucionais, relatórios de desempenho fornecidos pala Coordenação de Registros Escolares/CORES, atas de Conselho de Classe e documentos acerca do Programa, com o intuito de verificar os aspectos políticos, legais e pedagógicos que norteiam a execução do PROEJA.

Na segunda fase da pesquisa, manteremos contato com os diversos segmentos envolvidos no programa: docentes, discentes, coordenações do curso e do CEPROEJA, nas diversas gestões administrativas. Com o propósito de privilegiar as falas dos sujeitos sociais, optamos pela aplicação de entrevista, a qual pode ser definida como um processo de interação social entre duas pessoas na qual uma delas, o entrevistador, tem por objetivo a obtenção de informações por parte do outro, o entrevistado (HAGUETTE, 1987). Com o uso de várias fontes de coleta de dados, considerado por Yin (2005) um ponto forte para obtenção das evidências, teremos condições de estabelecer uma triangulação das informações, a partir da perspectiva dos vários sujeitos sociais.

\section{RESULTADOS E DISCUSSÕES}

No Brasil, a história do ensino profissional está relacionada com a divisão do trabalho e de classes sociais, onde a elite tem formação intelectual para conduzir os rumos do país e a classe trabalhadora recebe formação para realizar o trabalho manual, por meio da venda da sua força de trabalho. Divisão tão demarcada que, somente na década de 1950 foi possível àqueles que completassem os cursos profissionalizantes continuar sua formação nos níveis superiores.

Em se tratando do estado da Bahia, esse histórico se inicia com a criação do "Liceu de Artes e Ofícios" de Salvador, em 1872; em 1909 é inaugurada a "Escola de Aprendizes Artífices". Os processos de mudanças na legislação educacional no país, a partir de 1942, estendeu o ensino profissionalizante ao 2을 ciclo, transformando o Liceu em Escola Técnica de Salvador (IFBA, 2013). Paulatinamente, as Escolas Técnicas foram transformadas em Escolas Técnicas Federais, passando a fazer parte da Rede Federal de Estabelecimentos de Ensino Industrial. A Escola Técnica de Salvador foi incorporada à Rede Federal em 1965, através da Lei $n^{\circ} 4.759$, e passou a ser denominada Escola Técnica Federal da Bahia - ETFBA.

No ano de 1969, as Escolas Técnicas Federais iniciam a oferta de cursos profissionais superiores de curta duração. Em 1993, a ETFBA em junção com o CENTEC transforma-se em CEFETBA, se expandindo em 1994 com a criação e implantação de quatro Unidades de Ensino Descentralizadas - UNEDs, dentre elas a de Barreiras. Mais recentemente, a Lei no 11.892/2008, instituiu a Rede Federal de Educação Profissional, Científica e Tecnológica e transformou os CEFETs, dentre eles o Instituto Federal de Educação, Ciência e Tecnologia da Bahia. Atualmente, em decorrência do processo de expansão, o IFBA conta com 20 campi, espalhando pelo estado, e 
a Reitoria, em Salvador.

O IFBA, então CEFET - UNED-Barreiras, no ano de 2006, passou a oferecer o curso Técnico em Eletromecânica na modalidade PROEJA. ${ }^{1}$ O Projeto Pedagógico do Curso (PPC) foi elaborado em setembro de 2006, menos de dois meses após a promulgação do Decreto № 5.840/2006. Chama-nos a atenção que o PPC não traz em sua justificativa ou em outros elementos, nenhuma referência à EJA, tampouco de maneira integrada com a Educação Profissional e o Ensino Médio.

Ao Considerar que o Documento Base do PROEJA somente é publicado em 2007, nos parece parcialmente compreensível, mas causa preocupação que, após a publicação de tal documento não houve revisão do PPC, estando em desacordo com as diretrizes dispostas no Documento Base do PROEJA e se distanciando já na proposta curricular, dos objetivos do Programa. Ainda em relação à documentação interna do IFBA, observamos que o Projeto Pedagógico Institucional, finalizado em 2013, poucas referências ao PROEJA, não trazendo qualquer diagnóstico da situação preocupante acerca da oferta e permanência estudantil nesta modalidade dentro do Instituto.

Quanto à forma de ingresso, destacamos que no período analisado, foram diversas as formas de seleção para o acesso ao curso. ${ }^{2}$ A esse respeito, Klinski (2009) constatou que nos IFs de todo o Brasil o processo de seleção é bastante diversificado, sugerindo que seja repensada essa forma de seleção para compor os grupos participantes do programa.

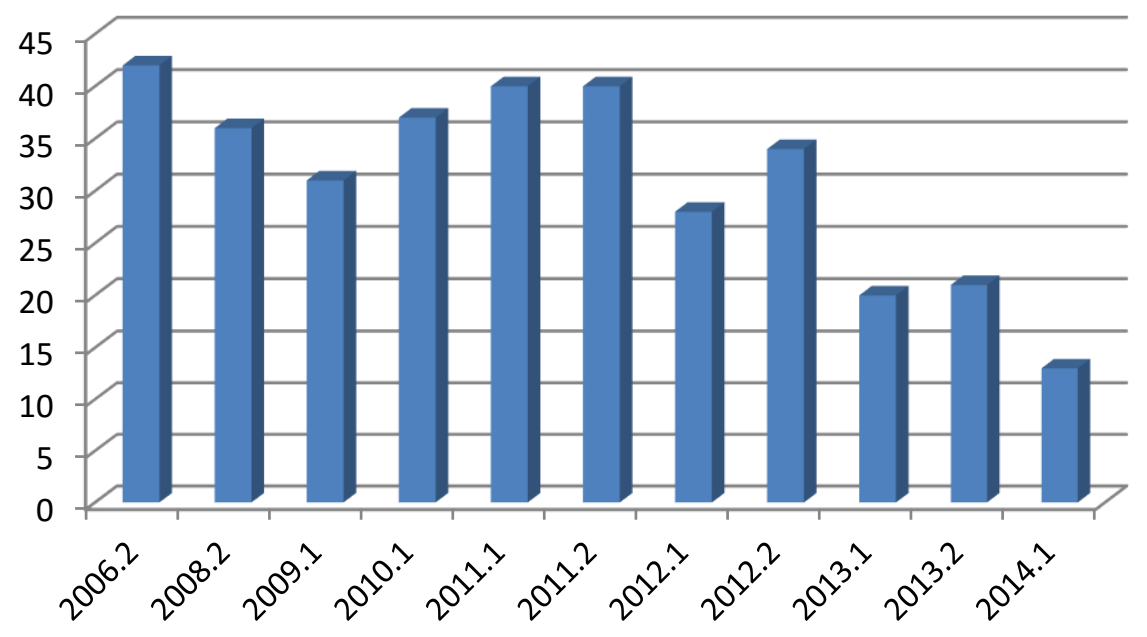

Gráfico 1 - Quantidade de ingressos por ano

No que diz respeito ao oferecimento, verificamos que existiu irregularidade na oferta, não havendo turma em 2007. Assim, em oito anos formaram-se onze turmas. Conforme observamos no Gráfico 1, a primeira turma apresentou o número elevado de ingressos (42), seguido de queda nas duas entradas seguintes (2008.2 e 2009.1), com elevação a partir de 2010.1. Em 2012.1 há uma

\footnotetext{
${ }^{1}$ No IFBA mais três campus oferecem o PROEJA: Salvador, Vitória da Conquista e Santo Amaro, ministrando os cursos de Saneamento, Informática e Segurança do Trabalho, respectivamente.

${ }^{2}$ No Edital de Seleção 2010 (IFBA, 2010), o processo seletivo do PROEJA ocorreu mediante aplicação de prova e redação, compondo $60 \%$ da nota final; e análise socioeducativa com peso de $40 \%$. No ano de 2011 , mediante processo seletivo simplificado, a avaliação compreendeu a realização de uma redação (60\%) e análise socioeducativa (40\%). Em 2014, o processo seletivo foi desenvolvido em quatro etapas: Preenchimento do questionário socioeducativo; Participação em Palestra Informativa; Prova de Redação e Entrevista, realizadas por assistente social e pedagogo do IFBA (IFBA, 2014).
} 
queda significativa no número de ingressos (28) até que a última turma ingressante (2014) soma apenas treze estudantes matriculados. É possível conjecturar que desde a sua implantação, o curso PROEJA vem reduzindo o nível de atração, sendo necessário investigar quais os motivos desse quadro.

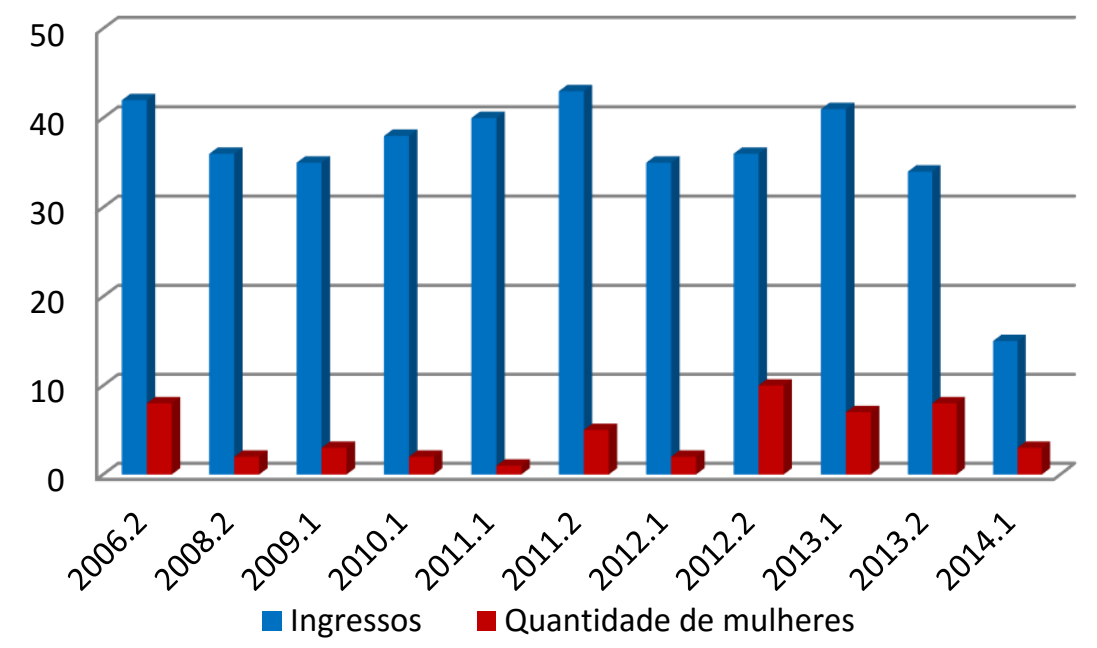

Gráfico 2 - Quantidade de mulheres ingressas no curso por ano

Neste cenário, conforme vemos no Gráfico 2, todas as turmas apresentam pequena presença de mulheres, totalizando 51 mulheres ingressantes durante o período estudado, sendo que a menor quantidade ocorreu em 2011.1, com a entrada de apenas uma mulher e em 2012.2 a maior quantidade, dez mulheres. Esta situação é um retrato da divisão sexual do trabalho, haja vista que o curso de Eletromecânica é considerado um curso masculino.

O perfil dos ingressos no PROEJA Campus de Barreiras nos anos de 2006, 2013 e 2014, ${ }^{3}$ nos permitiu compreender um pouco a trajetória social e educacional desses estudantes. ${ }^{4}$ Entre os ingressos no PROEJA predomina estudantes do sexo masculino, com percentual acima de $85 \%$. A reduzida presença feminina na entrada e permanência no curso de Eletromecânica pode ser compreendida a partir da história da educação das mulheres no Brasil.

A esse respeito, verifica-se que somente no ano de 1827 foi regulamentado o ensino feminino no Brasil, permitindo o ingresso de mulheres na escola, em classes separadas por sexo, onde aos meninos eram ensinadas as disciplinas de geometria e matemática e às meninas eram ensinadas prendas domésticas, regras de etiqueta e noções de moral. As reivindicações das feministas no final do século XIX possibilitou que em 1879, as jovens mulheres tivessem acesso ao Ensino Superior (YANNOULAS, 2013). Esta divisão curricular até os dias atuais influencia uma cultura que divide as ocupações e profissões de acordo com o sexo, tornando a questão do gênero um aspecto de exclusão educacional e profissional.

Quanto à idade, ocorreu uma predominância na faixa etária de 18 a 20 anos (46,7\%), em 2006. Nos anos seguintes, a maior incidência foi nas faixas de 18 a 24 anos (64,1\%) e 25 a 31 anos

\footnotetext{
${ }^{3}$ Em 2006, o perfil foi realizado pelo Serviço Social, por meio da aplicação do questionário. Em 2013 e 2014 foram elaborados a partir dos dados coletados na entrevista social e pedagógica.

${ }^{4}$ A noção de trajetória é compreendida aqui como um processo que comporta dimensão individual e social (BERTAUX, 1979).
} 
(42,9\%), respectivamente. O perfil dos sujeitos que se pretende beneficiar com a implementação dessa política pública educacional, para inscrição e matrícula no PREOJA, é ter ensino fundamental concluído; ter idade compatível com a definida no projeto e em conformidade com a legislação sobre EJA.

No caso do curso de Eletromecânica, a maioria dos estudantes possuía o ensino médio completo, realizado em escola pública, com índice acima de 83,0\%, sendo que no ano de 2014 todos (as) os (as) ingressos (as) no PROEJA já tinham concluído o referido nível de ensino. Observase, conforme apontado em alguns estudos (FERNANDES, 2011; KLINSKI, 2009), a ausência de estudante com o perfil típico dos encontrados na EJA na rede Federal, cabe - mesmo que tardiamente -, repensar as ofertas até então existentes e promover a inclusão desses sujeitos, rompendo com o ciclo das apartações educacionais, na educação profissional e tecnológica.

A distorção com relação ao público alvo do PROEJA tem sido apontada como um problema nacional. Klinski (2009) elege essa questão como objeto de estudo, concluindo que entre os elementos que conduziram os estudantes a procurar o curso do PROEJA, mesmo tendo finalizado o ensino médio, estariam as trajetórias formativas e profissionais descontínuas; a baixa qualidade do ensino médio cursado; a imagem de excelência do IF na oferta da educação profissional e o processo seletivo; dentre outros.

Para a maioria dos (as) estudantes que ingressou no curso de Eletromecânica, a Instituição foi escolhida em virtude de sua credibilidade. Ao passo que os motivos da procura pelo curso foram indicados como sendo por causa do mercado de trabalho; voltar a estudar; afinidade; vocação e a realização pessoal.

Ao analisar a trajetória das onze turmas, notamos que apenas a primeira apresenta índice de reprovação maior do que o de aprovação. Contudo, do total de turmas, menos de metade (45\%) alcançou aprovação de $50 \%$ ou mais no primeiro módulo do curso, o que significa um índice elevado de reprovação. Os índices de estudantes desistentes, que não ultrapassaram a primeira etapa do curso também são elevados.

O acompanhamento pedagógico do PROEJA, por meio da participação nos Conselhos de Classe Finais, nos levou a considerar as informações das Planilhas Finais. Constatamos que um significativo quantitativo de estudantes é aprovado pelo Conselho, o que implica em dificuldades que não foram superadas durante o processo de ensino-aprendizagem. As planilhas finais analisadas parcialmente, entre 2011.2 e 2014.2, indicam uma média de 38,7\% aprovados pelo conselho neste período.

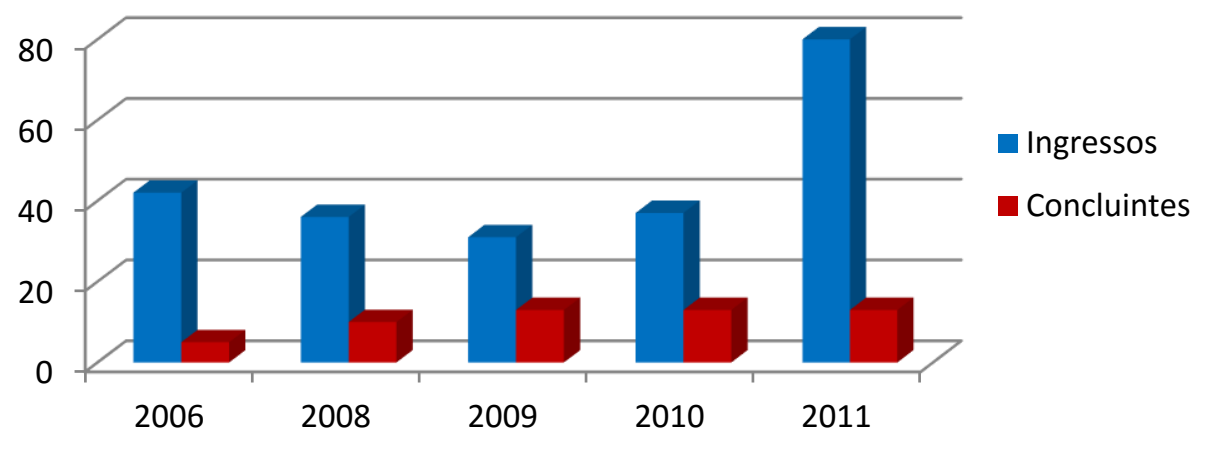

Gráfico 3 - Quantidade de concluintes entre 2006 e 2011 


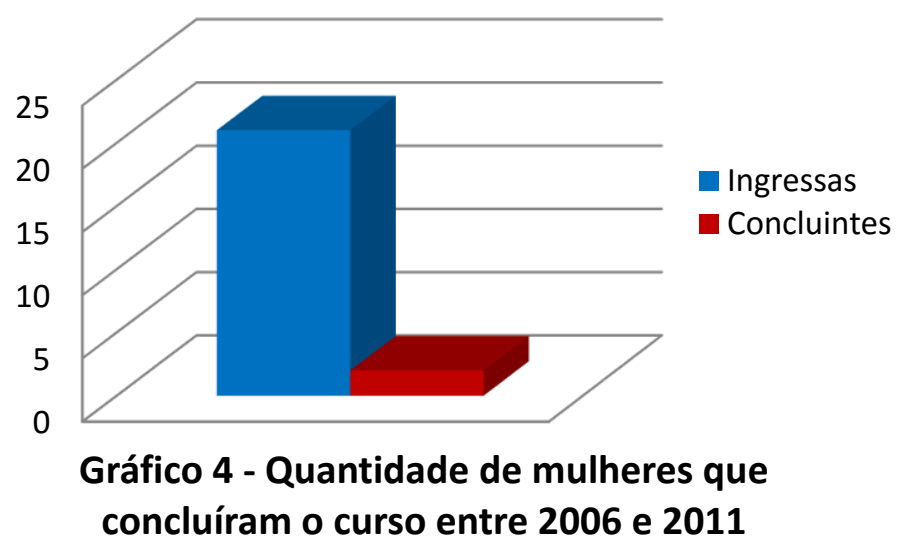

Por fim, constatamos nessa fase inicial da pesquisa que, entre 2006 e 2011, dos (as) 226 estudantes matriculados (as) no PROEJA apenas 56 concluíram, ou seja, 24,5\% (Gráfico 3) sendo que dois ainda estão em estágio, ${ }^{5}$ e dentre apenas 02 mulheres concluíram (Gráfico 4). Os dados nos possibilitam inferir que o PROEJA no Campus Barreiras obteve pouco êxito no que trata da finalização do curso, com um alto índice de abandono, problema levantado quando da implantação do Programa nacionalmente, conforme informações encontradas no site do MEC (BRASIL/MEC, 2015).

\section{CONCLUSÃO}

Ao procedermos à análise dos primeiros achados da pesquisa a luz do referencial teórico e documento, podemos inferir que em quase uma década o Programa não conseguiu ser consolidado no Campus Barreiras, com relação à demanda por parte dos (as) estudantes e público alvo, em particular. Constatamos um quadro de elevado índice de reprovação/retenção e evasão logo no primeiro módulo do curso.

A fase no estudo não nos permite apresentar conclusões definitivas; pelo contrário, várias indagações sugiram, como: quais os motivos para alta reprovação e desistência entre os (as) estudantes? $\mathrm{O}$ que tem levado egressos do ensino médio a realizarem um curso com o mesmo nível de ensino? Quais os motivos para a pouca presença e baixa conclusão entre as mulheres?

Observamos que no site do MEC poucos dados recentes são apresentados acerca do PROEJA, esse quadro pode ser atribuído, como analisa Franzoi et all (2013, p. 89), a ênfase ou quase exclusividade que o governo estaria dando ao PRONATEC, provocando o refluxo do primeiro programa. Acreditam que a aposta do governo federal na expressividade numérica do PRONATEC tem feito sombra ao PROEJA. Em suma, enfatizam que "o 'esquecimento' do PROEJA diante do PRONATEC pode pôr a perder os ganhos que esse programa trouxe ao público do EJA, tanto em qualidade quanto acesso às escolas federais onde antes não tinham vez nem lugar". Representando ainda um retrocesso nas políticas de formação dos (as) trabalhadores.

A longa história da educação profissional está atrelada ao tecnicismo, da qual o IFBA está inserido desde os primórdios. Assim, mais de um século de história de Ensino Técnico produtor de

\footnotetext{
${ }^{5}$ No campus do IFBA Vitória da Conquista, Fernandes (2011) verificou que 37,5\% dos estudantes ingressos na primeira turma, em 2006, concluíram o curso.
} 
mão de obra especializada para atender às demandas do mercado não será rompida via decreto, mas pelo estabelecimento de uma nova cultura educacional, pautada no trabalho como princípio educativo e considerando diversas questões deste sujeito trabalhador, da qual enfatizamos a questão de gênero.

Observarmos mediante análise do Projeto Pedagógico Institucional do IFBA (2013) que o PROEJA será tratado de maneira muito pouco aprofundada, em uma abordagem superficial e sem um diagnóstico da situação do funcionamento do Programa, haja vista que não se efetivou enquanto Política Pública e obteve pouco acompanhamento na implantação na Rede Federal. Ainda que o Projeto Pedagógico do Curso não dialoga com a proposta do PROEJA, tampouco apresenta diagnóstico ou elabora uma proposta que realmente inclua o público alvo no Instituto.

Em relação a pouca presença de mulheres no ingresso e permanência do curso, observamos a naturalização da divisão social do trabalho em sexos, já que o curso de Eletromecânica não é considerado "para mulheres", o que se manifesta ainda mais cruelmente no ínfimo número de mulheres concluinte: apenas duas.

Acreditamos que ao avançar no desenvolvimento da pesquisa teremos melhores condições de compreender a temática do PROEJA, considerando as dimensões da política de educação profissional no Brasil, de trajetória educacional, social e pedagógica dos/as estudantes, envolvendo o currículo, prática docente e gestão administrativa.

\section{REFERÊNCIAS}

1. BERTAUX, Daniel. Destinos pessoais e estrutura de classe: para uma crítica da antroponomia política. Tradução Maria Jose da S. Lindoso. RJ: Zahar Editores, 1979.

2. BOGDAN, Roberto C.; BILKLEN, Sari K. Investigação qualitativa em educação: introdução à teoria e aos métodos. Tradução Maria José Alves et al. Portugal: Porto Editora, 1997.

3. BRASIL, CNE/CEB. Resolução № 1: Estabelece Diretrizes Curriculares Nacionais para a Educação de Jovens e Adultos, 2000.

4. BRASIL, MEC/SETEC. PROEJA. Programa Nacional de Integração da Educação Profissional com a Educação Básica na modalidade de Educação de jovens e Adultos. Formação inicial e continuada/Ensino Fundamental. Documento Base. Brasília, 2007a.

5. BRASIL, MEC/SETEC. PROEJA. Programa Nacional de Integração da Educação Profissional com a Educação Básica na modalidade de Educação de jovens e Adultos. Formação inicial e continuada/Ensino Médio. Documento Base. Brasília, 2007b.

6. CARDOSO, Ruth. Aventuras de antropólogos em campo ou como escapar das armadilhas do método. In: Paz e Terra, 1986. . (Org.). A aventura antropológica: teoria e pesquisa. 4. ed. Rio de Janeiro:

7. CEFET-BA/ UNED-Barreiras. Projeto Pedagógico do Curso Técnico de Nível Médio em Eletromecânica Modalidade PROEJA. Barreiras: CEFET-BA, 2006.

8. FERNANDES, Marta Q. O Instituto Federal de Educação, Ciência e Tecnologia da Bahia e o PROEJA: o caso do campus de Vitoria da Conquista. Dissertação (Mestrado em Educação), Faculdade de Educação, Universidade Federal de São Carlos, 2011.

9. FRANZOI, Naira L. Et al. PROEJA e PRONATEC: ciclo de políticas, políticas recicladas. Políticas 
Educativas, Porto Alegre, v. 6, n. 2, p 84-100, 2013. ISSN: 1982-3207.

10. FRIGOTTO, Gaudêncio; CIAVATTA, Maria; RAMOS, Marise. O trabalho como princípio educativo no projeto de educação integral de trabalhadores. 2005, Disponível em: escolanet.com.br. Acesso em: 05/05/2015.

11. GRAMSCl, Antônio. Os intelectuais e a organização da cultura. Tradução Carlos Nelson Coutinho, 4a ed. Civilização brasileira, 1982.

12. HAGUETTE, Teresa Maria Frota. Metodologias Qualitativas na Sociologia. Petrópolis: Vozes, 1987.

13. IFBA. Edital de Abertura de Inscrição do Processo Seletivo/2010. Salvador: IFBA, 2009.

14. IFBA. Edital de Abertura de Inscrição do Processo Seletivo/2014 Cursos Técnicos Integrados Modalidade PROEJA, 2013. Salvador: IFBA, 2014.

15. IFBA. Projeto Pedagógico Institucional do IFBA. Salvador: IFBA, 2013.

16. IFBA. Regulamento de Inscrição do Processo Seletivo Simplificado para o Curso Técnico de Eletromecânica modalidade de Educação de jovens e Adultos/2011. Barreiras: IFBA, 2011.

17. KERGOAT, Daniéle. Divisão sexual do trabalho e relações sociais de sexo. In: HIRATA, Helena et al (orgs.). Dicionário Crítico do Feminismo. São Paulo: Editora UNESP, 2009. p. 67.

18. KLINSKI, Claudia dos S. Ingresso e permanência de alunos com ensino médio completo do Instituto Federal Sul-Rio-Grandense/Campus Charqueadas. Dissertação (Mestrado em Educação). Faculdade de Educação, universidade Federal do Rio Grande do Sul, 2009.

19. RUAS, Thatiane Santos; GARÍGLIO, José Ângelo. Relações de gênero no currículo do PROEJA: estudo de caso de um curso Técnico de Mecânica de uma Instituição Federal de MG. Disponível em: http://www.senept.cefetmg.br/galerias/Anais_2010/Artigos/GT7/ RELACOES_ DE_ GENERO .pdf. Acesso em: 08/2015.

20. YANNOULAS, Silvia Cristina (Coord.). Trabalhadoras - Análise da Feminização das Profissões e Ocupações. Brasília: Editorial Abaré, 2013.

21. YIN, Robert K. Estudo de caso: planejamento e métodos. Tradução Daniel Grassi. 3. ed. Porto Alegre: Bookman, 2005. 